\title{
Respostas fisiológicas de plantas amazônicas de regiões alagadas às mudanças climáticas globais
}

\author{
ADRIANA GRANDIS, SIMONE GODOI e MARCOS SILVEIRA BUCKERIDGE ${ }^{1,2}$
}

(recebido: 28 de fevereiro de 2008; aceito: 28 de outubro de 2009)

\begin{abstract}
Physiological responses of Amazonian flooded plants to the global climate change). According to the last report of IPCC (Intergovernmental Panel of Climatic Change, 2007) an increase in atmospheric $\mathrm{CO}_{2}$ concentration to ca. $0.072 \%$ is predicted to occur until the middle of this century. As a result, a tandem elevation of temperature of ca. $+3{ }^{\circ} \mathrm{C}$ and a decrease in precipitation are to be expected. It has also been suggested that this scenario may lead to a gradual substitution of the tropical forest for savanna-like vegetation in Eastern parts of the Amazon. Within this perspective, a worth question is how the tree species that make up the Amazonian floodplains will respond to the global climatic change? Although predictions have been quite pessimistic, flooding of part of the Amazon will continue to occur for several years and it is important to understand its synergistic effects within the scenario of climate change. In this work, features related to plant metabolism and hormonal signaling during flooding is revised, and the possible effects that the climatic changes might have on plants from the Amazon are discussed. The information available in the literature suggests that under flooding, plants tend to mobilize storage compounds to supply carbon demand needed for maintenance metabolism under the effect of stress caused by the lack of oxygen. In contrast, under elevated $\mathrm{CO}_{2}$ concentration, plants tend to increase photosynthesis and biomass. With an increase of about $3{ }^{\circ} \mathrm{C}$ these parameters may increase even more. Alternatively, with flooding, there is a general decrease in growth potential and it is possible that while favorable conditions of elevated $\mathrm{CO}_{2}$ and temperature prevail, the positive effects may be counterbalanced by the negative effects of flooding. Thus, the physiological responses might be imperceptible or promote further growth up to the middle of the $21^{\text {st }}$ Century for most species that occur in the floodplains. However, if temperature and $\mathrm{CO}_{2}$ levels surpass the threshold of optimal conditions for most plants, a decrease in physiological activity is to be expected.
\end{abstract}

Key words - Amazonian, carbon sequestration, drought, global change, global warming

RESUMO - (Respostas fisiológicas de plantas amazônicas de regiões alagadas às mudanças climáticas globais). Conforme previsões do último relatório do IPCC (Intergovernmental Panel of Climatic Change) em 2007, até meados deste século haverá um aumento na concentração de $\mathrm{CO}_{2}$ na atmosfera podendo chegar a $720 \mu \mathrm{mol} \mathrm{mol}^{-1}$. Consequentemente haverá uma elevação da temperatura de até $+3{ }^{\circ} \mathrm{C}$, o que ocorrerá em conjunto com mudanças no padrão de precipitação. O mesmo relatório sugere que isto poderá acarretar uma substituição gradual da floresta tropical por vegetação similar a uma savana na parte oriental da Amazônia, porém nada é conclusivo. Diante dessas possibilidades, pergunta-se-Como as espécies de árvores que compõem as regiões de alagamento da Amazônia irão responder às alterações climáticas por vir? Apesar dessas previsões serem pessimistas, o alagamento ainda ocorrerá por vários anos na Amazônia e é de grande importância compreender os efeitos do alagamento sobre as respostas fisiológicas das plantas num contexto das mudanças climáticas. Os principais efeitos sobre a sinalização metabólica e hormonal durante o alagamento são revisados e os possíveis efeitos que as mudanças climáticas poderão ter sobre as plantas amazônicas são discutidos. As informações existentes sugerem que sob alagamento, as plantas tendem a mobilizar reservas para suprir a demanda de carbono necessário para a manutenção do metabolismo sob o estresse da falta de oxigênio. Até certo limite, com o aumento da concentração de $\mathrm{CO}_{2}$, as plantas tendem a fazer mais fotossíntese e a produzir mais biomassa, que poderão aumentar ainda mais com um acréscimo de temperatura de até $3{ }^{\circ} \mathrm{C}$. Alternativamente, com o alagamento, há uma diminuição geral do potencial de crescimento e é possível que quando em condições de $\mathrm{CO}_{2}$ e temperatura elevados os efeitos positivo e negativo se somem. Com isso, as respostas fisiológicas poderão ser amenizadas ou, ainda, promover maior crescimento para a maioria das espécies de regiões alagáveis até o meio do século. Porém, quando a temperatura e o $\mathrm{CO}_{2}$ atingirem valores acima dos ótimos para a maioria das plantas, estas possivelmente diminuirão a atividade fisiológica.

Palavras-chave - alagamento, Amazônia, aquecimento global, mudanças climáticas, seqüestro de carbono

1. Instituto de Biociências, Departamento de Botânica, Universidade de São Paulo, Rua do Matão, 277, Cidade Universitária, São Paulo, SP, Brasil.

2._Correspondência para: msbuck@usp.br

\section{Introdução}

As plantas que crescem em atmosfera de $\mathrm{CO}_{2}$ elevado exibem um aumento de biomassa devido a 
maiores taxas de fotossíntese. No ano 2000, nosso grupo de pesquisa iniciou investigações sobre as respostas fisiológicas do jatobá (Hymenaea courbaril L.), uma árvore que ocorre em toda a região Neotropical, submetido a altas concentrações de gás carbônico no ar (aproximadamente $720 \mu \mathrm{mol} \mathrm{mol}{ }^{-1}$ ). Descobrimos que nessas condições as plantas jovens do jatobá aumentam sua fotossíntese, o que culmina num aumento de biomassa e se relaciona com nossas observações de que há mais açúcares nas folhas e mais celulose no caule (Costa 2004, Buckeridge et al. 2008). Concluímos, assim, que o jatobá seqüestra mais carbono da atmosfera enriquecida de $\mathrm{CO}_{2}$ quando jovem. No entanto, observamos também que quando há mobilização de reservas e o crescimento ocorre principalmente à custa de uma fonte "interna" de carbono (no caso das plântulas do jatobá, os cotilédones), o efeito da elevação do $\mathrm{CO}_{2}$ no ambiente externo é significativamente menor (Aidar et al. 2002). A mobilização de reservas exerce um efeito de tamponamento do efeito fertilizante do $\mathrm{CO}_{2}$ que entra na planta através da fotossíntese. Estudos mais aprofundados sobre essa espécie e, paralelamente com outras espécies arbóreas pertencentes a diferentes grupos funcionais em relação à sucessão ecológica na Mata Atlântica (feijão-do-mato, pau-jacaré, guapuruvu e jacarandá-da-bahia), mostraram que os efeitos sobre estas árvores são muito similares aos efeitos observados para o jatobá. Para essas espécies, medimos a quantidade de carbono em cada órgão das plantas crescidas em concentrações de $\mathrm{CO}_{2}$ ambiente $\left(370 \mu \mathrm{mol} \mathrm{mol}^{-1}\right)$ e elevado $\left(720 \mu \mathrm{mol} \mathrm{mol}^{-1}\right)$ e observamos que há um acúmulo de carbono nas espécies que estão em elevadas concentrações de $\mathrm{CO}_{2}$ (Buckeridge et al. 2007).

No entanto, para a maioria das espécies tropicais avaliamos apenas os efeitos do gás carbônico e, para que possamos inferir o comportamento das plantas frente às mudanças climáticas globais, será necessário conhecer mais sobre como elas responderão ao aumento de temperatura e, também, às mudanças na disponibilidade hídrica.

Regiões da Amazônia estão sujeitas anualmente a um período de alagamento que pode ultrapassar 10 metros, onde plântulas e árvores ficam alagadas ou submersas por períodos que podem durar até sete meses a cada ano (Junk 1989). A temperatura média anual é de $26,6^{\circ} \mathrm{C}$, com pequenas flutuações, a média de chuva é de $2100 \mathrm{~mm} \mathrm{ano}^{-1}$ (Ribeiro \& Adis 1984) e a intensidade da luz pode atingir até $3000 \mu \mathrm{mol} \mathrm{m} \mathrm{m}^{-2} \mathrm{~s}^{-1}$ acima da superfície da água, ao meio dia (Furch et al. 1985). Esses valores representam condições favoráveis para o crescimento de árvores, porém é nessa fase que o alagamento ocorre, o que implica numa necessidade de adaptação das plantas a essa mudança no ambiente (Joly 1991, Parolin et al. 2004).

Mesmo com previsões de que em certas regiões da Amazônia ocorrerá diminuição na disponibilidade de água (IPCC 2007), vale ressaltar que serão grandes as mudanças nos padrões de aquecimento, vento e precipitação, que acarretarão eventos extremos do clima, afetando diretamente a duração e intensidade do alagamento e da estação de seca (IPCC 2007, Nobre et al. 2007).

No presente trabalho, são revisados os principais efeitos sobre a sinalização metabólica e hormonal durante o alagamento e estes conhecimentos são usados para uma discussão sobre os possíveis efeitos que as mudanças climáticas poderão ter sobre as plantas amazônicas. Ainda há poucos resultados sobre os efeitos de atmosfera de $\mathrm{CO}_{2}$ elevado sobre plantas amazônicas em condições que simulem, ao menos em parte, as condições esperadas com as mudanças climáticas globais. No entanto, há algum conhecimento sobre as respostas ao alagamento de várias espécies e pode-se especular sobre o que poderá acontecer com as mudanças climáticas esperadas para a primeira parte do século XXI. A seguir serão examinados alguns dos mecanismos fisiológicos e bioquímicos relacionados às repostas de plantas amazônicas ao alagamento e, em seguida, serão discutidas as possíveis respostas que as plantas amazônicas sob alagamento poderão apresentar ao aumento na concentração de $\mathrm{CO}_{2}$ atmosférico, à temperatura e à combinação dos três fatores.

\section{Sinalização metabólica e hormonal durante $o$ alagamento}

Ao sofrer alagamento, as plantas produzem sinais metabólicos de vários tipos, em resposta à diminuição dos níveis endógenos de oxigênio. Nesse período elas alteram sua arquitetura, anatomia, metabolismo e crescimento como estratégia de sobrevivência (Bailey-Serres \& Voesenek 2008).

A sinalização pode ocorrer de duas maneiras: pela diminuição da concentração de oxigênio e por um aumento de etileno. Embora as respostas das plantas pela sinalização do etileno sejam bem definidas, os resultados obtidos sobre a sinalização de oxigênio são descobertas recentes (Visser \& Voesenek 2004). Como conseqüência da queda nos níveis de oxigênio, há uma regulação negativa do ciclo dos ácidos tricarboxílicos (o ciclo de Krebs) que são os principais mecanismos geradores de esqueletos de carbono para a síntese de 
compostos do metabolismo secundário das plantas, de onde vêm os hormônios vegetais.

No entanto, além das modificações metabólicas e morfológicas, acredita-se que o oxigênio funcione, também, como um sinal independente do fluxo de energia regulando diferentes partes do metabolismo e informando a condição de alagamento. Segundo Visser \& Voesenek (2004), o fato de uma diminuição no fluxo metabólico ocorrer não indica que a disponibilidade de $\mathrm{O}_{2}$ foi sinalizada na planta. Esses autores observaram que o baixo Km da citocromo c oxidase (enzima responsável pelo transporte de elétrons para a redução da molécula de $\mathrm{O}_{2}$, transformando-a em duas moléculas de água) garante que a sua atividade continue enquanto o $\mathrm{O}_{2}$ ainda está disponível na planta. Isso indica que há outro mecanismo de sinalização que é independente da respiração, causada por modificações na cadeia de transporte de elétrons, que diminui o consumo de ATP e $\mathrm{O}_{2}$ por outras enzimas que evitam que a hipóxia cause a morte celular (Visser \& Voesenek 2004).

Klok et al. (2002) estudaram as alterações nos padrões de expressão gênica em plantas de Arabidopsis sob alagamento. As principais classes de genes afetadas foram: (1) genes envolvidos no metabolismo do etanol; (2) genes que desempenham funções no processo "pós-injúria"; (3) genes relacionados ao metabolismo de etileno, incluindo a sua síntese e sinalização e (4) genes envolvidos no processo de morte celular programada e alongamento da parede celular. Segundo Visser \& Voesenek (2004), as duas primeiras classes de genes poderiam ser interpretadas como pré-adaptativas, pois dariam continuidade à produção de energia em futuros episódios de alagamento, aumentando as chances de sobrevivência da planta. As categorias 3 e 4 estão relacionadas com a formação de aerênquima, o que prepara a planta para um período mais longo de alagamento.

Parolin et al. (2004) em uma revisão sobre espécies da Amazônia, aponta diversos trabalhos que envolvem essas respostas fisiológicas e alterações morfoanatômicas das raízes em resposta ao alagamento, indicando que esses genes localizados por Klok et al. (2002) são encontrados também nas plantas tropicais.

Estudando componentes voláteis na atmosfera da Amazônia, Kesselmeier e colaborador (Kesselmeier \& Staudt 1999, Kesselmeier 2001) observaram que plantas amazônicas, após a anóxia das raízes, apresentavam altos níveis de etanol nesse órgão que eram transportados para as folhas formando acetaldeídos e ácido acético como intermediários. Esses componentes por sua vez são dispersos na atmosfera e podem ser sinalizadores de estresse sofrido pelas plantas. Além disso, gases como o oxigênio, $\mathrm{CO}_{2}$ e o etileno têm uma difusão lenta na água (Gibbs \& Greenway 2003) e, assim, as plantas quando alagadas, enfrentam uma grande barreira na difusão desses gases através da água, restringindo a respiração aeróbia. Dessa forma, a concentração endógena dos hormônios gasosos como o etileno aumenta nos tecidos envoltos por água (Fukao \& Bailey-Serres 2004), desencadeando reações metabólicas diversificadas.

Uma descoberta fascinante é que plantas expostas à baixa concentração de oxigênio apresentam maior expressão do gene que codifica para a hemoglobina (Nie \& Hill 1997). Esses autores observaram que os níveis de mRNA de hemoglobina em tecido de aleurona de cevada eram mais altos em baixo oxigênio e além disso, que o controle da expressão parece não estar relacionado diretamente ao oxigênio, mas aos níveis de ATP (o principal composto de armazenamento de energia no metabolismo) no tecido. Mais recentemente, Hunt et al. (2002) e Dordas et al. (2003) observaram que hemoglobinas aparecem em tecidos em crescimento rápido. É possível que as taxas respiratórias relativamente baixas em tecidos vegetais ocorram em condições em que o transporte de oxigênio não seja necessário, mas acima de certo limiar, por exemplo, sob condições de hipóxia geradas por alagamento, as hemoglobinas seriam responsáveis pelo transporte desse gás. Outra hipótese, levantada por Nie \& Hill (1997), é a de que a hemoglobina funcionaria com um mecanismo sensor de oxigênio nos tecidos.

Os segundos mensageiros candidatos a agirem durante o alagamento seriam os níveis de ATP, o declínio no $\mathrm{pH}$ citossólico (provavelmente causado pelo acúmulo de lactato) e as aquaporinas (Tournaire-Roux et al. 2003). Esses autores propõem que um período de anóxia faz com que haja acidose (diminuição do $\mathrm{pH}$ ) citossólica, evento que sinaliza a expressão que inibe a produção das aquaporinas, um dos subgrupos dentro da classe das Intrinsic Membrane Proteins - IMPs responsável pelo transporte de água através de membranas. Essas proteínas, supostamente, seriam responsáveis por mediar a inibição do transporte de água pelas raízes.

Foi observado que o controle da queda do $\mathrm{pH}$ citosólico é promovido pelo balanço entre a produção de lactato e etanol. O acúmulo de lactato sob baixas concentrações de $\mathrm{O}_{2}$ ocorre antes da produção de etanol nas raízes, quando há uma queda no $\mathrm{pH}$ de 7,5 para 6,8 . Esse declínio favorece o ótimo catalítico da piruvatodescarboxilase que modula a produção de lactato para a produção de etanol (Roberts et al. 1989). Nesse mesmo experimento, utilizando plantas deficientes em álcool desidrogenase nas suas raízes, quando são submetidas 
a anóxia, continuaram a produzir lactato, falhando na estabilização do $\mathrm{pH}$ citosólico. Isso resulta em uma rápida acidificação e morte celular, mostrando que o interruptor entre lactato e a fermentação etanólica é o ponto crítico na manutenção do pH celular (Roberts et al. 1989).

Outro mecanismo de sinalização pode ocorrer pela via da produção de peróxido de hidrogênio $\left(\mathrm{H}_{2} \mathrm{O}_{2}\right)$ (Baxter-Burrel et al. 2000). Blokhina e colaboradores (Blokhina et al. 2001) demostraram que em resposta à anóxia, as plantas de trigo apresentam um acúmulo acentuado de $\mathrm{H}_{2} \mathrm{O}_{2}$ no apoplasto de meristemas da raiz. Níveis baixos de oxigênio aumentam a concentração de $\mathrm{H}_{2} \mathrm{O}_{2}$ fazendo com que dois genes, um chamado Rop e outro RopGAP4, tenham suas expressões controladas. Este último gene regula negativamente a expressão do primeiro e o primeiro controla positivamente o último. Segundo Visser \& Voesenek (2004), esse sistema funciona como um sistema reostatizado que regula os níveis endógenos de $\mathrm{H}_{2} \mathrm{O}_{2}$ sendo crucial para o tecido pois, se a concentração de peróxido de hidrogênio aumentar muito no tecido, o programa de morte celular poderá ser disparado.

A diminuição nos níveis de oxigênio desencadeia uma cascata de sinais que acaba afetando o metabolismo de produção de etileno. Em uma série de experimentos com raízes de plantas de milho sob hipóxia, no último artigo da série (He et al. 1996) foi observado que quando ocorre hipóxia, há um aumento na síntese de etileno pelo aumento da atividade de ACC sintase, o que resulta em um aumento na atividade de celulase que contribui para a degradação da parede celular e a formação de aerênquima do tipo lisígeno. Os autores ainda bloquearam a síntese de etileno usando aminoetoxilvinilglicina (AVG), o que suprimiu o aumento de celulase e a formação do aerênquima. É importante lembrar que a parede celular não é formada somente por celulose, mas por vários outros componentes como pectinas e hemiceluloses, que formam uma rede complexa ao redor de cada célula vegetal (Carpita \& Gibeaut 1993, Albersheim et al. 1996, Buckeridge 2006, Buckeridge et al. 2008b). Esses outros componentes da parede celular também são alterados na formação do aerênquima e, de fato, alguns autores observaram aumentos nos níveis de atividade enzimática de pectinase, xilanase e xiloglucano-endotransglicosilase (XTH) sob condições de hipóxia (Saab \& Sachs 1996, Bragina et al. 2003).

O etileno também induz a hipertrofia de lenticelas (Bradford \& Yang 1981), que ocorrem geralmente na base dos caules, e induzem a formação de dois tipos aerênquima: $\mathrm{O}$ lisígeno, que é formado pela morte de células corticais, e o esquizógeno, oriundo da conexão de células, que formam colunas contínuas para armazenamento e transporte de gases (Joly 1991).

Outro elemento importante na cascata de sinalização durante o alagamento é o cálcio. He e colaboradores (He et al. 1996) também mostraram que a manipulação da concentração e fluxo de cálcio citoplasmático pode alterar a capacidade de resposta de raízes de milho à hipóxia com a formação de aerênquima. Alterar os níveis de cálcio é importante não somente para os mecanismos de sinalização intracelulares mas, também, para que as pectinas, que formam complexos com o cálcio na parede celular, se tornem acessíveis ao ataque de enzimas.

Um dos efeitos da exposição de plantas a hipóxia é a produção de raízes adventícias. Um experimento em câmara de crescimento com plantas amazônicas mostrou que o alagamento pode induzir a produção de adaptações típicas contra estresse causado por inundações como, por exemplo, a produção de raízes adventícias e hipertrofia do caule (Waldhoff et al. 1998). A formação deste tipo de raiz é classicamente associada às auxinas. Quando uma planta é alagada, o mau funcionamento das raízes leva grande parte destas à morte e ao mesmo tempo, como ocorre em varias espécies, a indução da produção de raízes adventícias que possuem aerênquima (Visser \& Voesenek 2004).

Como as auxinas são produzidas principalmente no ápice da parte aérea e transportadas para as raízes, enquanto as citocininas são produzidas nas raízes e transportadas para as folhas, o alagamento das raízes pode alterar drasticamente o balanço hormonal na planta. O transporte das auxinas parece ser realmente crucial para as respostas ao alagamento e isto foi demonstrado por McDonald \& Visser (2003), que usaram um inibidor de transporte de auxina (ácido naftilftalâmico - NPA) e verificaram uma diminuição na produção de raízes adventícias. Uma possível explicação é a falta do sinal dado pela auxina para a mobilização de reservas de carbono (ver também Santos et al. 2004) nas raízes, reservas estas que serão utilizadas para o desenvolvimento das raízes adventícias.

As citocininas são provavelmente importantes nesse contexto, mas há poucos experimentos em que estes hormônios tenham sido utilizados ou medidos. Hipoteticamente, a morte das raízes pode causar um desequilibro hormonal entre as concentrações de auxina e citocinina na planta sob alagamento por falta de produção de citocininas. Teoricamente, uma diminuição na proporção de raízes deveria induzir a uma diminuição na longevidade das folhas, pois a citocinina parece controlar o processo de senescência foliar (Wingler et al. 1998). 
Pelo exposto, fica claro que os principais mecanismos de sinalização seriam a disponibilidade de oxigênio seguida de uma rede de sinais paralelos que culminam com o disparo de alterações celulares em tecidos específicos, através da ativação do processo de morte celular programada. Esse processo induz à morte celular do parênquima, formando o aerênquima que abre espaço para o transporte de gases. Em um trabalho utilizando gás pressurizado $\left(\mathrm{SF}_{6}\right)$ no caule de plantas amazônicas, foi verificado o transporte de gases do caule para as raízes, mostrando que há permeabilidade de gases entre a base do caule até as raízes, que contribuem para a aeração das raízes de espécies que sofrem um gradiente de inundação (Graffmann et al. 2008). Paralelamente, a morte das raízes provocaria um desequilíbrio hormonal no sentido de aumentar a razão auxinas : citocininas e com isso ocorreria a indução da formação de raízes adventícias (Voesenek et al. 2003).

Todo esse processo parece ter como intermediário o etileno, que é induzido pela via de sinalização independente da produção de energia. A existência de duas vias, uma dependente e outra independente da produção de energia, parece ser fundamental para que a planta apresente tolerância ao alagamento. Enquanto a primeira emite sinais para que os tecidos se transformem, a segunda induz a expressão de um conjunto de genes que garantem o suprimento de energia suficiente para que a planta execute as transformações necessárias, ou seja, a formação de aerênquima e a indução de raízes adventícias.

A maioria dos experimentos realizados sobre vias de sinalização sob alagamento utilizou plantas como milho, arroz, arabidopsis, girassol e, ainda, é pouco o que se sabe, do ponto de vista da sinalização celular e hormonal, sobre os mecanismos envolvidos na aclimatação de plantas amazônicas ao alagamento. Entender esses mecanismos em plantas amazônicas é de grande importância e deverá ter um impacto positivo na compreensão sobre como a biodiversidade amazônica responde ao alagamento e às mudanças no clima, levando em consideração o fato desse ser um importante sinal sazonal do ambiente que perdura por cerca de sete meses. A aclimatação das plantas ao alagamento provavelmente só ocorre porque o processo é lento, permitindo respostas das plantas que crescem em condições climáticas com altas temperaturas e alta umidade. Com taxas de crescimento altas, as plantas amazônicas parecem responder rapidamente com mecanismos similares aos mencionados. A fase aquática representa para as plantas um período desfavorável, que implica na queda das folhas (possivelmente pela ação do etileno), reduzindo a produção de novas folhas (balanço hormonal) e a assimilação fotossintética (Parolin 2000). Porém, muitas espécies produzem flores e frutos em resposta à redução fotossintética durante vários meses (Kubitzki \& Ziburski 1994). Isso sugere que nesses períodos a planta utilize reservas, uma vez que há um fluxo reduzido de carbono através da via fotossintética para suprir a demanda requerida pelos processos de floração e frutificação.

\section{Mudanças climáticas e as respostas de plantas sob alagamento}

A emissão de carbono relacionada à queima de combustíveis fósseis vem levando a um aumento na concentração atmosférica de $\mathrm{CO}_{2}$ em todo o planeta. Por volta da década de 1930, a concentração era de $0,028 \%$ e atualmente já se mede $0,039 \%$. Como o $\mathrm{CO}_{2}$ é um dos principais gases responsáveis pelo efeito estufa, o aumento na sua concentração vem sendo associado a um aumento de temperatura na superfície terrestre. $\mathrm{O}$ aumento de temperatura afeta, em vários pontos do planeta, os níveis de precipitação, podendo assim alterar drasticamente a quantidade esperada de chuvas em determinados pontos da Amazônia. As previsões atuais sugerem que poderá haver diminuição considerável de precipitação na Amazônia e isto culminará com um aumento médio de temperatura entre 2 e $6{ }^{\circ} \mathrm{C}$ (IPCC 2007).

As formas de impacto das mudanças climáticas sobre as plantas na Amazônia poderiam ser decompostas como: (1) efeitos do aumento no $\mathrm{CO}_{2}$ atmosférico; (2) efeitos do aumento na temperatura e (3) efeitos do aumento ou diminuição na disponibilidade de água.

Abordar a Amazônia no contexto das mudanças climáticas é extremamente difícil, pois se trata de uma região de grandes proporções geográficas e com peculiaridades, principalmente no que concerne ao que acontecerá com a temperatura e as chuvas. Em outras palavras, é importante ter em mente que em diferentes regiões amazônicas, a ação da combinação dos três fatores deverá ocorrer com intensidades bastante diferentes.

Outro cuidado que deve ser tomado é com possíveis extrapolações para o comportamento da floresta. É óbvio que as plantas são importantes na floresta, mas é necessário lembrar que elas são apenas uma parte do ecossistema. Dessa forma, extrapolações para a floresta teriam que levar em consideração os ciclos biogeoquímicos e as dinâmicas das populações de predadores, herbívoros, dispersores e polinizadores em um cenário de redes integradas (Buckeridge et al. 2008a). Os ciclos biogeoquímicos 
afetam a disponibilidade geral de nutrientes e os mecanismos de competição entre as espécies afetam a biomassa e a reprodução das plantas. Tudo isto pode ter reflexos nas cadeias alimentares, podendo ou não alterar a biodiversidade (Buckeridge et al. 2007).

Em geral, o que foi descrito até então, é que as plantas sob alagamento diminuem seu rendimento energético, pois as raízes têm problemas para funcionar sob anóxia e alteram o padrão de desenvolvimento, pois há dificuldades na manutenção do fluxo energético nos tecidos. No caso de árvores que são parcialmente alagadas, a anóxia ocorre principalmente nas raízes. Para a espécie Senna reticulata (Willd.) H. S. Irwin \& Barneby (Parolim 2001) as plântulas têm como estratégia de sobrevivência o crescimento rápido, pois não suportam a submersão, mas para isto necessitam estocar e mobilizar reservas com grande eficiência de forma a suprir a alta demanda energética e de nutrientes para altas taxas de crescimento. Há, também, espécies de plantas que sobrevivem quando estão completamente submersas como, por exemplo, Himatanthus sucuuba (Spruce ex Muell. Arg.) Woodson, encontrada em regiões de várzea e em terra firme (Ferreira et al. 2009a). Dentro dessa espécie, Ferreira et al. (2007) encontraram populações com diferentes respostas adaptativas ao alagamento, dependendo da região que se encontram. Em casos como esses, ocorreria um processo seletivo em que, a diminuição no alagamento, levaria à dominância dos membros da população de terra firme em relação aos da área alagada (Ferreira et al. 2009b). Isso reforça a idéia de que há um componente genético importante, nas espécies da Amazônia, que deverá interferir nas respostas em nível da floresta. Tais respostas, ainda que sejam essencialmente de ordem fisiológica, têm como determinante a distribuição de certos genes nas populações das espécies.

Há muito pouco conhecimento sobre os aspectos da fisiologia e bioquímica de árvores de regiões tropicais sob alagamento nas condições esperadas de mudanças climáticas globais. Por isso, neste momento podemos apenas especular sobre como as plantas amazônicas responderão às mudanças climáticas, propondo que estudos que auxiliem a compreender melhor como a floresta como um todo poderá responder.

Cada área da ciência usa os conhecimentos disponíveis em diferentes níveis de organização para inferir as respostas futuras das florestas às mudanças climáticas globais. Os meteorologistas utilizam os dados e, principalmente, os modelos disponíveis e sugerem respostas da biodiversidade às alterações nas concentrações de $\mathrm{CO}_{2}$, temperatura e precipitação
(Sampaio et al. 2008). Ecólogos utilizam as observações disponíveis em diferentes níveis para sugerir comportamentos das florestas (Fearnside 2008, Ometto \& Martinelli 2008, Scarano 2008). Essas são estratégias de extrapolação que poderiam ser chamadas de top-down. A outra forma de produzir modelos interpretativos de como a floresta pode responder poderia ser chamada de bottom-up e consiste em utilizar informações ao nível da célula e do organismo (Ceccantini et al. 2008, de Souza et al. 2008, Buckeridge et al. 2008a) para extrapolar modelos de funcionamento em nível de floresta. As duas estratégias apresentam incertezas e para diminuí-las será necessário interpretar os fenômenos utilizando informações e aproximações de modelos com estratégias diferentes. O presente trabalho pretende contribuir com a estratégia bottom-up.

Assumindo que, de forma geral, durante o período de alagamento na Amazônia haja uma diminuição da taxa de crescimento das plantas, devido principalmente às limitações de aeração das raízes, os efeitos das mudanças climáticas e do alagamento se somariam e, provavelmente, favoreceriam o crescimento, ou ainda, manteriam o sistema funcionando com o mesmo rendimento hoje existente, pois o metabolismo tenderia a aumentar com o acréscimo de temperatura. Porém, aqui não levamos em consideração os eventos extremos de seca e pulsos maiores de inundação, que podem levar à extinção espécies que não suportariam essas condições.

Atualmente já se sabe muita coisa sobre como as plantas irão responder ao aumento de $\mathrm{CO}_{2}$, mas esse conhecimento foi produzido principalmente para espécies cultivadas ou plantas do hemisfério norte (Wand et al. 1999). Mesmo assim, como os mecanismos fotossintéticos, respiratórios e de crescimento parecem ser conservados entre as plantas, algumas extrapolações podem ser feitas com um risco de erro relativamente baixo.

Em uma revisão, Springer \& Ward (2007) apresentaram resultados de mais de 60 trabalhos sobre a resposta do tempo de floração de plantas expostas à altas concentrações de $\mathrm{CO}_{2}$, tanto de grandes culturas como de espécies selvagens. Os autores sugerem que, no futuro, elevadas concentrações de $\mathrm{CO}_{2}$ atmosférico poderão influenciar no tempo de floração, principalmente se acoplados com outros fatores ambientais que podem ser alterados, como a temperatura e umidade (Morellato 2008). Estudos feitos com soja, a planta mais estudada quanto aos efeitos das mudanças climáticas (Ainsworth et al. 2002), indicam que os processos de floração e frutificação não serão grandemente afetados ao ponto de aumentar significativamente a biomassa. Segundo 
Long et al. (2006), há uma queda no efeito acumulador de biomassa nas folhas, no caule, nos frutos e nas sementes, nesta ordem. Tal gradiente está provavelmente relacionado ao fato de que o carbono acumulado a mais nas folhas, devido a maior taxa fotossintética, vai sendo gasto para suprir a demanda energética crescente relacionada ao processo reprodutivo das plantas.

Elevadas concentrações $\mathrm{CO}_{2}$ estimulam a taxa fotossintética da maioria das espécies de plantas e espera-se que haja um maior acúmulo de biomassa nas plantas submetidas a essas condições. Essa previsão está de acordo com a maioria dos resultados experimentais obtidos em condições ótimas de crescimento (Poorter \& Pérez-Soba 2002). No entanto, o crescimento das plantas é menos estimulado em função do aumento da taxa de fotossíntese por unidade de área foliar. Isso ocorre porque plantas em elevadas concentrações de $\mathrm{CO}_{2}$ têm sua área foliar reduzida por unidade de biomassa apresentada diminuindo, assim, a quantidade relativa da maquinaria fotossintética. A redução da taxa fotossintética se dá principalmente pelo aumento no acúmulo de carboidratos não-estruturais nas folhas. A amplitude de resposta do crescimento em relação ao elevado de $\mathrm{CO}_{2}$ depende de cada espécie, porém a maioria das espécies de crescimento rápido, respondem positivamente ao $\mathrm{CO}_{2}$, com um aumento de biomassa de, aproximadamente, 47\% (Poorter \& Pérez-Soba 2002).

As espécies de crescimento lento apresentam geralmente menos acúmulo de biomassa do que espécies de crescimento rápido, lembrando que o $\mathrm{CO}_{2}$ não é o único fator que influencia no crescimento mas, também, que outros fatores ambientais, como luz, nutrientes e água, contribuem na assimilação de carbono (Buckeridge et al. 2008a).

$\mathrm{O}$ aumento na concentração de $\mathrm{CO}_{2}$, em geral, vem levando a aumentos das taxas fotossintéticas e do acúmulo de biomassa em algumas plantas brasileiras (Buckeridge et al. 2007). Em atmosfera enriquecida com $600 \mu \mathrm{mol} \mathrm{mol}{ }^{-1}$ de $\mathrm{CO}_{2}$, duas espécies de árvores amazônicas Tectona grandis L. f. (Verbenaceae) e Pseudobombax septenatum (Jacq.) Dugand (Bombacaceae) apresentaram um aumento nas taxas de assimilação fotossintética de $28 \mathrm{e}$ $52 \%$, respectivamente (Holtum \& Winter 2003).

Outras duas espécies que ocorrem na região amazônica foram estudadas quanto às respostas a altas concentrações de $\mathrm{CO}_{2}$, o jatobá (Hymenaea courbaril) e o matapasto (Senna reticulata). A primeira é uma árvore do estágio final da sucessão ecológica e a segunda uma pioneira, ou seja, do início desse processo. Em experimentos com plântulas de $S$. reticulata crescendo em $760 \mu \mathrm{mol} \mathrm{mol}{ }^{-1}$ de $\mathrm{CO}_{2}$ houve um aumento de $30 \%$ na produção de biomassa total em 75 dias de experimento (A. Grandis, B.C. Arenque \& M.S. Buckeridge, dados não publicados). No caso de $H$. courbaril, Aidar et al. (2002) observaram que há um aumento de $60 \%$ na fotossíntese quando plântulas foram crescidas em $720 \mu \mathrm{mol} \mathrm{mol}^{-1}$ de $\mathrm{CO}_{2}$. Houve um aumento na biomassa e nos níveis de açúcares endógenos (sacarose, amido e celulose) da ordem de 30\% (Costa 2004, Buckeridge et al. 2008). A disponibilidade de reservas parece interferir diretamente sobre o efeito do $\mathrm{CO}_{2}$, pois plântulas de jatobá que estavam mobilizando as reservas cotiledonares não mostraram as mesmas diferenças. Nos últimos cinco anos, nosso grupo de pesquisas vem demonstrando que outras espécies de árvores da Mata Atlântica, pertencentes a família Leguminosae, apresentam o mesmo padrão que o jatobá e matapasto, possibilitando assim alguma extrapolação para a Amazônia, já que esses mesmos gêneros também ocorrem nessa região (Buckeridge et al. 2008).

$\mathrm{O}$ fato de que a presença de mobilização de reservas interfere no efeito geral causado pelo aumento de $\mathrm{CO}_{2}$ atmosférico (Aidar et al. 2002) pode ser importante no contexto do alagamento, pois, como mencionado anteriormente, uma das maneiras que as plantas sob alagamento podem apresentar como forma de tolerar esse estresse seria o acúmulo de reservas nas raízes, que poderiam ser utilizadas para desenvolver raízes adventícias (Ferreira et al. 2009b). Nesse contexto, é plausível sugerir que o efeito fertilizante do $\mathrm{CO}_{2}$, esperado em concentrações atmosféricas maiores, possa contribuir nos casos em que as reservas das raízes, ou de outras partes da planta sob alagamento, passem a ser mobilizadas. É importante ressaltar o caráter especulativo do que foi exposto acima, o que denota a necessidade da realização de experimentos para testar a hipótese levantada, levando em consideração toda a relação fonte e dreno dessas plantas.

Mesmo para regiões fora da Amazônia, há poucos experimentos combinando altas concentrações de $\mathrm{CO}_{2}$ e alagamento em plantas. Um deles foi feito com a árvore Taxodium distichum (L.) Rich., uma espécie de cipreste do sudeste do EUA (Megonigal et al. 2005). O objetivo era comparar as respostas de uma microalga com uma árvore partindo da hipótese de que a primeira responderia com um aumento do crescimento, enquanto a segunda não. A hipótese foi confirmada mostrando que há um equilíbrio entre os efeitos benéficos do $\mathrm{CO}_{2}$ e os efeitos negativos do alagamento. Como $T$. distichum é uma espécie adaptada ao alagamento (chamada de cipreste do pântano), neste aspecto, pelo menos, poderíamos comparar com espécies da Amazônia. Mas, essa comparação deve ser feita com parcimônia, pois os 
ciprestes têm respostas distintas de dicotiledôneas em alto $\mathrm{CO}_{2}$ e não são facilmente comparáveis a árvores amazônicas. Por outro lado, se a hipótese da interferência da mobilização das reservas internas de carbono for válida para a maioria das plantas, inclusive coníferas, é possível que um mecanismo geral possa ajudar a explicar a ausência de resposta ao alto $\mathrm{CO}_{2}$ sob alagamento.

Como ainda não há experimentos reportados com plantas amazônicas em altas concentrações de $\mathrm{CO}_{2}$ e, ao mesmo tempo, alagamento, a única possibilidade é especular com base nos poucos dados existentes para outras espécies. Como o alagamento tem um efeito negativo sobre o crescimento, limitando o fluxo de energia através do metabolismo vegetal e o $\mathrm{CO}_{2}$ tem o efeito contrário, fertilizando a planta e fazendo com que ela cresça mais, é bastante provável que na maioria dos casos, os efeitos se compensem mutuamente, como ocorreu com $T$. distichum, e não sejam observadas grandes alterações fisiológicas quando (e se) somente estes dois fatores atuarem.

\section{O efeito tríplice $\left(\mathrm{CO}_{2}\right.$, temperatura e alagamento)}

Ainda que o número de trabalhos publicados sobre o efeito de altas concentrações de $\mathrm{CO}_{2}$ seja muito grande (Wand et al. 1999), experimentos com aumento de temperatura e principalmente a combinação entre temperatura e $\mathrm{CO}_{2}$ são raros. Norby \& Luo (2004) colocam esse problema como algo que provavelmente deverá ser abordado primeiro ao estilo "caso a caso" para que, posteriormente se possam tirar conclusões mais amplas.

Do ponto de vista fisiológico e de maneira geral, o aumento de temperatura em condições atuais tende a aumentar a assimilação fotossintética, uma vez que os sistemas fotossintéticos das plantas tendem a se aproximar de seus ótimos de funcionamento. Em conjunto, aumentam também a respiração de manutenção e a respiração de crescimento das plantas (Norby \& Luo 2004).

Lloyd \& Farquhar (2008) produziram um modelo sobre os efeitos do aumento da temperatura e das concentrações de $\mathrm{CO}_{2}$ na fisiologia de espécies arbóreas tropicais. Os autores sugeriram que embora possam ocorrer reduções nas taxas fotossintéticas com um aumento na temperatura da folha acima de $30^{\circ} \mathrm{C}$, essas reduções são causadas principalmente pelo aumento na respiração, redução da condutância estomática em resposta ao alto déficit de pressão de vapor das folhas.
Eles ainda estimaram que o aumento na fotossíntese associado ao aumento do $\mathrm{CO}_{2}$ nas próximas décadas deverá compensar qualquer redução na produtividade da fotossíntese. Embora o modelo calcule um mecanismo plausível para a aceleração na dinâmica de florestas tropicais, deve haver um limite para o tamanho máximo que uma floresta possa atingir. A incapacidade de compreender a base das variações na superfície de todas as reservas de carbono e a seca na floresta Amazônica (Saatchi et al. 2007) limita a nossa compreensão de como qualquer sequestro de carbono continue a ocorrer.

Poorter \& Pérez-Soba (2001) realizaram experimentos com várias espécies do hemisfério norte e chegaram à conclusão de que quando as temperaturas estão próximas ao ótimo de uma espécie, o aumento relativo causado na biomassa por $\mathrm{CO}_{2}$ elevado é maior do que quando a temperatura está abaixo ou acima do ótimo para a espécie. Norby et al. (2000) examinaram as respostas de duas espécies de Acer (A. rubrum L. e $A$. saccharum Marsh.) à combinação de alto $\mathrm{CO}_{2} \mathrm{e}$ alta temperatura $\left(4^{\circ} \mathrm{C}\right.$ a mais do que a temperatura ambiente). Em ambos os casos o aumento de temperatura diminuiu a produção de biomassa pelas árvores ao passo que o $\mathrm{CO}_{2}$ elevado reverteu parcialmente esse efeito. Experimentos recentes (A. Yepes \& M. Buckeridge, resultados não publicados) com plantas jovens de jatobá mostraram que a temperatura $\left(+3{ }^{\circ} \mathrm{C}\right)$ tem um efeito de um aumento de $34 \%$ na biomassa total em relação ao tratamento de temperatura ambiente. Esses autores verificaram que a combinação de elevado $\mathrm{CO}_{2}$ e elavada temperatura ampliaram a faixa de ótimo de temperatura da fotossíntese caracterizando, assim, a existência de interação entre os dois fatores.

A hipótese de que o efeito do $\mathrm{CO}_{2}$ em interação com a temperatura depende dos ótimos para o funcionamento do metabolismo (fotossintético e respiratório) de cada espécie, serviu de argumento para Norby \& Luo (2004), de que realmente teremos que examinar as respostas caso a caso.

Deve-se salientar, no entanto, que em um trabalho recente Enquist e colaboradores (Enquist et al. 2007) utilizaram um modelo de escalonamento com base em equações alométricas e concluíram que as plantas no hemisfério norte apresentam os metabolismos fotossintético e respiratório fortemente acoplados e que a razão entre Assimilação Máxima $\left(\mathrm{A}_{\max }\right)$ e Respiração Máxima $\left(\mathrm{R}_{\max }\right)$ não é alterada nas diferentes latitudes no hemisfério norte. Em outras palavras, a razão $A_{\max }: R_{\max }$ é independente da temperatura. Esses autores discutem o fato de haver varias evidências apontando para a existência de uma "convergência de funcionamento" 
entre os ecossistemas, o que significa que nestes há um alto grau de resiliência. Um exemplo interessante foi apontado por Huxman et al. (2004), que quando se comparam vários biomas com precipitação na faixa de 50 a $3000 \mathrm{~mm} \mathrm{ano}^{-1}$, há uma convergência para uma eficiência do uso da água da chuva ajustada à máxima produção de biomassa durante os períodos secos. De fato, tem sido proposto que a probabilidade de existência de compensações ecológicas aumenta com o nível hierárquico de organização, aumentando, portanto, da espécie, para o grupo funcional e para a comunidade. Isso pode sugerir que, apesar das variações na temperatura, disponibilidade hídrica e nas concentrações de $\mathrm{CO}_{2}$, os sistemas relacionados ao uso da água provavelmente permanecerão similares.

No contexto das respostas das plantas amazônicas às mudanças climáticas, será de fundamental importância saber se tais princípios são ou não aplicáveis. Teoricamente, o nível de complexidade dos biomas amazônicos pode ser consideravelmente maior do que aquele encontrado no hemisfério norte, com a ressalva de que altos índices de biodiversidade também significam alto nível de redundância de espécies e, consequentemente, de redundância funcional. Quanto maior o nível de complexidade, mais intrincado o sistema de integração das redes de relações ecológicas e mais resistente se torna o sistema às alterações por flutuação de fatores externos (Barabasi 2003, Buckeridge 2008).

Em termos fisiológicos é possível que os efeitos do aumento da concentração de $\mathrm{CO}_{2}$ e temperaturas elevadas se somem positivamente e talvez ocorra um aumento no crescimento (principalmente nas espécies de crescimento rápido), acoplados com o período em que as espécies não estão submetidas ao alagamento (A. Yepes \& M.S. Buckeridge, dados não publicados).

Por outro lado, se de fato ocorrer uma diminuição do pulso de inundação, poderá haver um favorecimento temporário daquelas espécies que são submetidas a essas condições, uma vez que estas não são espécies que se desenvolvem melhor sob alagamento, mas ao contrário, são espécies que trabalham em condições sub-ótimas (em relação aos seus potenciais máximos). Com menor freqüência ou mesmo a ausência de alagamento (previsões climáticas indicam diminuição da precipitação a este ponto para várias regiões na Amazônia), as plantas terão uma condutância estomática menor, uma maior disponibilidade de $\mathrm{CO}_{2}$ e maior eficiência no uso da água, resultando em maiores taxas de crescimento e maior acúmulo de biomassa. $\mathrm{Ou}$, ainda, se eventos climáticos extremos ocorrerem de fato, espécies com maior disponibilidade de reservas (obtidas durante a fase não alagada) poderão suportar maiores períodos de alagamento e, também, aquelas que não suportam total submersão poderão mobilizar carbono excedente para a síntese e expansão de parede celular resultando no alongamento do caule para sobreviver.

Contudo, se os níveis de emissão de gases do efeito estufa continuarem aumentando, em meados do século XXI a temperatura deverá atingir valores acima dos ótimos para a maioria das plantas. Nessas condições, espécies de regiões alagáveis possivelmente diminuirão a atividade metabólica.

Agradecimentos - Os autores agradecem o financiamento da Eletronorte, MCT, CNPq e Fapesp. M.S. Buckeridge e A. Grandis são bolsistas do CNPq e S. Godoi é bolsista de pós-doutorado da Fapesp. Os autores agradecem as valiosas críticas de B.C. Arenque e C.S. Ferreira.

\section{Referências bibliográficas}

AIDAR, M.P.M., MARTINEZ, C.A., COSTA, A.C., COSTA, P.M.F., DIETRICH, S.M.C. \& BUCKERIDGE, M.S. 2002. Effect of atmospheric $\mathrm{CO}_{2}$ enrichment on the establishment of seedlings of jatobá, Hymenaea courbaril L. (Leguminosae, Caesalpinioideae). Biota Neotropica 1. http://www.biotaneotropica.org.br/v2n1/en/abstract? article+BN01602012002 (acesso em 12/12/2007).

AINSWORTH, E.A., DAVEY, P.A., BERNACCH, C.J., DERMODY, O.C., HEATON, E.A., MOORE, D.J., MORGAN, P.B., NAIDU, S.L., YOORA, H.S., ZHU, X.G., CURTINS, P. \& LONG, S.P. 2002. A meta-analysis of elevated $\left[\mathrm{CO}_{2}\right]$ effects on soybean (Glycine max) physiology, growth and yield. Global Change Biology 8:695-709.

ALBERSHEIM, P., DARVILL, A.G., O’NEILL, M.A., SCHOLS, H.A. \& VORAGEN, A.G.J. 1996. A hypothesis: The same six polysaccharides are components of the primary cell walls of all higher plants. In Pectins and pectinases (J. Visser \& A.G.J. Voragen, eds.). Elsevier Science, Amsterdan, p.47-55.

BAILEY-SERRES, J. \& VOESENEK, L.A.C.J. 2008. Flooding stress: aclimations and genetic diversity. Annual Review Plant Biology 59:313-339.

BARABASI, A.L. 2003. Linked: how everything is connected to everything else and what it means for business, science and everyday life. Plume, New York.

BAXTER-BURREL, A., YANG, Z., SPRINGER, P.S. \& BAILEI-SERRES, J., 2000. RopGAP4-dependent Rop GTPase rheostat control of Arabidopsis oxygen deprivation tolerance. Science 296:2026-2028.

BLOKHINA, O.B., CHIRKOVA, T.V. \& FAGERSTEDT, K.V. 2001. Anoxic stress leads to hydrogen peroxide formation in plant cells. Journal of Experimental Botany 52:1179-90. 
BRADFORD, K.J. \& YANG. S.F. 1981. Physiological responses of plants to waterlogging. HortScience 16:25-30.

BRAGINA, T.V., RODIONOVA, N.A. \& GRINIEVA, G.M. 2003. Ethylene production and activation of hydrolytic enzymes during acclimation of maize seedlings to partial flooding. Russian Journal of Plant Physiology 50:794-798.

BUCKERIDGE, M.S. 2006. Implications of emergence, degeneracy and redundancy for the modeling of the plant cell wall. In The Science and the lore of the plant cell wall: biosynthesis, structure and function. (T. Hayashi, org.). Boca Raton: Brown Walker Press, p.41-47.

BUCKERIDGE, M.S. 2008. Mudanças climáticas, biodiversidade e sociedade: como a teoria de redes pode ajudar a compreender o presente e planejar o futuro? Multiciência v.8 http://www.multiciencia.unicamp.br/ artigos_08/editorial_8.pdf

BUCKERIDGE, M.S., MORTARI, L.C. \& MACHADO, M.R. 2007. Respostas fisiológicas de plantas às mudanças climáticas: alterações no balanço de carbono nas plantas podem afetar o ecossistema? In Fenologia - Ferramenta para conservação e manejo de recursos vegetais arbóreos (G.M. Rego, R.R.B. Negrelle \& L.P.C. Morellato, eds.). Embrapa Florestas, Colombo, p.1-13.

BUCKERIDGE, M.S., AIDAR, M.P.M., MARTINEZ, C.A. \& SILVA, E.A. 2008a. Respostas de plantas às mudanças climáticas globais. In Biologia das mudanças climáticas no Brasil (M.S. Buckeridge, org.). Ed. Rima, São Carlos, p.77-92.

BUCKERIDGE, M.S., CAVALARI, A.A. \& SILVA, G.B. 2008b. Parede Celular. In Fisiologia Vegetal (G.B. Kerbauy, ed.). Guanabara Koogan, Rio de Janeiro, p.165-168.

CARPITA, N.C. \& GIBEAUT, D.M. 1993. Structural models of primary cell walls in flowering plants: consistency of molecular structure with the physical properties of cell wall during growth. Plant Journal 3:1-30.

CECCANTINI, G.C.T., SCHONGART, J. \& SOLIZGAMBOA, C. 2008. Os anéis de crescimento das árvores: desvendando as mudanças climáticas. In Biologia das mudanças climáticas no Brasil (M.S. Buckeridge, org.). Ed. Rima, São Carlos, p.57-75.

COSTA, P.M.F. 2004. Efeitos da alta concentração de $\mathrm{CO}_{2}$ sobre o crescimento e o estabelecimento de plântulas do jatobá de mata Hymenaea courbaril L. var. stilbocarpa (Heyne) Lee \& Langenheim (Leguminosae, Caesalpinoideae, Detarieae). Dissertação de mestrado, Universidade Estadual de Campinas, Campinas.

DE SOUZA, A.P., GASPAR, M., SILVA, E.A., ULIAN, E.C., WACLAWOVSKY, A.J. \& NISHIYAMA JUNIOR, M.Y. 2008. Elevated $\mathrm{CO}_{2}$ increases photosynthesis, biomass and productivity, and modifies gene expression in sugarcane. Plant, Cell and Environment 31:11161127.
DORDAS, C., RIVOAL, J. \& HILL, R.D. 2003. Plant hemoglobins, nitric oxide and hypoxia stress. Annals of Botany 91:173-178.

ENQUIST, B.J., KERKHOFF, A.J., HUXMAN, T.E. \& ECONOMO, E.P. 2007. Adaptive differences in plant physiology and ecosystem paradoxes: insights from metabolic scaling theory. Global Change Biology 13:591-609.

FEARNSIDE, P.M. 2008. As mudanças climáticas globais e a floresta amazônica. In Biologia das mudanças climáticas no Brasil (M.S. Buckeridge, org.). Ed. Rima, São Carlos, p.131-150.

FERREIRA, C.S., PIEDADE, M.T.F., JUNK, W.J. \& PAROLIN, P. 2007. Floodplain and upland populations of Amazonian Himatanthus sucuuba: effects of flooding on germination, seedling growth and mortality. Environmental and Experimental Botany 60:477-483.

FERREIRA, C.S., PIEDADE, M.T.F., FRANCO, A.C., GONÇALVES, J.F.C. \& JUNK, W.J. 2009a. Adaptive strategies to tolerate prolonged flooding in seedlings of floodplain and upland populations of Himatanthus sucuuba, a Central Amazon tree. Aquatic Botany 90: 246-252.

FERREIRA, C.D.S., PIEDADE, M.T.F., TINÉ, M.A.S., ROSSATTO, D.R., PAROLIN, P. \& BUCKERIDGE, M.S. 2009b. The role of carbohydrates in seed germination and seedling establishment of Himatanthus sucuuba, an Amazonian tree with populations adapted to flooded and non-flooded conditions. Annals of Botany 104:1111-1119.

FUKAO, T. \& BAILEY-SERRES, J. 2004. Plant responses to hypoxia. Is survival a balancing act? Survival and anaerobic catabolism. Functional Plant Biology 30:1-47.

FURCH, B., CORREAA, A.F.F., NUNES, J.A.S.M. \& OTTO, K.R. 1985. Lichtklimadaten in drei aquatischen Ökosystemen verschiedener physikalisch-chemischer Beschaffenheit, I. Abschwächung, Rückstreuung und Vergleich zwischen Einstrahlung, Rückstrahlung und sphärisch gemessener Quantenstromdichte (PAR). Amazoniana 9:411-430.

GIBBS, J. \& GREENWAY, H. 2003. Review: Mechanisms of anoxia tolerance in plants. I. Growth, survival and anaerobic catabolism. Functional Plant Biology 30:1-47.

GRAFFMANN, K., GROSSE, W., JUNK, J. \& PAROLIN, P. 2008. Pressurized gas transport in Amazonian floodplain trees. Environmental and Experimental Botany 62: 371-375.

HE, C.J., MORGAN, P.W. \& DREW, M.C. 1996. Transduction of an ethylene signal is required for cell death and lysis in the root cortex of maize during aerenchyma formation induced by hypoxia. Plant Physiology 112:463-472.

HOLTUM, J.A.M. \& WINTER, K. 2003. Photosynthetic $\mathrm{CO}_{2}$ uptake in seedlings of two tropical tree species exposed to oscillating elevated concentrations of $\mathrm{CO}_{2}$. Planta 218:152-158. 
HUNT, P.W., KLOK, E.J., TREVASKIS, B., WATTS, R.A., ELLIS, M.H., PEACOCK, W.J. \& DENNIS, E.S. 2002. Increased level of hemoglobin 1 enhances survival of hypoxic stress and promotes early growth in Arabidopsis thaliana. Proceedings of the National Academical of Sciences 99:17197-17202.

HUXMAN, T.E., SMITH, M.D. \& FAY, P.A. 2004. Convergence across biomes to a common rain-use efficience. Nature 429:651-654.

IPCC. 2007. Intergovernmental Panel of Climatic Change WGII, fourth assessment report. http://www.ipcc.ch/ publications_and_data/publications_and_data_reports. htm (acesso em 01/12/2007).

JOLY, C.A. 1991. Flooding tolerance in tropical trees. In M.B. Jackson, D.D. Daves \& H. Lambers (eds.). Plant life under oxygen stress. Netherlands, SPB Academic Publishing, The Hague, p.23-34.

JUNK, W.J. 1989. Flood tolerance and tree distribution in central Amazonian floodplains. In Tropical forests: botanical dynamics, speciation and diversity (L.B. Holm-Nielsen, I.C. Nielsen \& H. Balslev, eds.). Academic Press, New York, p.47-64.

KESSELMEIER, J. 2001. Exchange of short-chain oxygenated volatile organic compounds (VOCs) between plants and the atmosphere: A compilation of field and laboratory studies. Journal of Atmospheric Chemistry 39:219-233.

KESSELMEIER, J. \& STAUDT, M. 1999. Biogenic volatile organic compounds (VOC): An overview on emission, physiology and ecology. Journal of Atmospheric Chemistry 33:23-88.

KLOK, E.J., WILSON, I.W., WILSON, D., CHAPMAN, S.C., EWING, R.M., SOMERVILLE, S.C., PEACOCK, W.J., DOFERUS, R. \& DENNIS, E.S. 2002. Expression profile analysis of the low-oxygen response in Arabidopsis root cultures. Plant Cell 14:2481-2494.

KUBITZKI, K. \& ZIBURSKI, A. 1994. Seed dispersal in flood plain forests of Amazonia. Biotropica 26:30-43.

LLOYD, J. \& FARQUHAR, G.D. 2008. Effects of rising temperatures and $\left[\mathrm{CO}_{2}\right]$ on the physiology of tropical forest trees. Philosophical and Transactions and Royal Society of London. Series B, Biological sciences 363:1811.

LONG, S.P., AINSWORTH, E.A., LEAKEY, A.D.B., NOSBERGER, J. \& ORT, D. 2006. Food for thought: lower-than-expected crop yield simulation with rising $\mathrm{CO}_{2}$ concentrations. Science 312:1918-1921.

MCDONALD, M.P. \& VISSER, E.J. 2003. A study of the interaction between auxin and ethylene in wildtype and transgenic ethylene insensitive tobacco during adventitious root formation induced by stagnant root zone conditions. Plant Biology 5:550-556.

MEGONIGAL, J.P., VANN, C.D. \& WOLF, A.A. 2005. Flooding constraints on tree (Taxodium distichum) and herb growth responses to elevated $\mathrm{CO}_{2}$. Wetlands $25: 430-438$.
MORELLATO, L.P.C. 2008. Fenologia de plantas e os efeitos das mudanças climáticas. In Biologia das mudanças climáticas no Brasil (M.S. Buckeridge, org.). Ed. Rima, São Carlos, p.181-191.

NIE, X.Z. \& HILL, R.D. 1997. Mitochondrial respiration and hemoglobin gene expression in barley aleurone tissue. Plant Physiology 114:835-840.

NOBRE, C.A., SAMPAIO, G. \& SALAZAR, L. 2007. Mudanças climáticas e Amazônia. Ciência e Cultura 59:22-27

NORBY, R.J. \& LUO, Y. 2004. Evaluating ecosystem responses to rising atmospheric $\mathrm{CO}_{2}$ and global warming in a multi-factor world. New Phytologist 162:281-293.

NORBY, R.J., LONG, T.M., HARTZ-RUBIN, J.S. \& O'NEILL, E.G. 2000. Nitrogen resorption in senescing tree leaves in a warmer, $\mathrm{CO}_{2}$-enriched atmosphere. Plant and Soil 224:15-29.

OMETTO, J.P.H.B. \& MATINELLI, L.A. 2008. Ciclos biogeoquímicos. In Biologia das mudanças climáticas no Brasil (M.S. Buckeridge, org.). Ed. Rima, São Carlos, p.29-53.

PAROLIN, P. 2000. Phenology and $\mathrm{CO}_{2}$-assimilation of trees in Central Amazonian Floodplains. Journal of Tropical Ecology 16:465-473.

PAROLIN, P. 2001. Senna reticulata, a pioneer tree from Amazonian várzea floodplains. Botanical Review 67: 239-254.

PAROLIN, P., DE SIMONE, O., HAASE, K., WALDHOFF, D., ROTTENBERGER, S., KUHN, U., KESSELMEIER, J., SCHMIDT, W., PIEDADE, M.T.F. \& JUNK, W.J. 2004. Central Amazon floodplain forests: tree survival in a pulsing system. The Botanical Review 70:357-380.

POORTER, H. \& PÈREZ-SOBA, N. 2001. The growth response of plants to elevated $\mathrm{CO}_{2}$ under non-optimal environmental conditions. Oecologia 129:1-20.

POORTER, H., \& PÈREZ-SOBA, M. 2002. Plant growth at elevated $\mathrm{CO}_{2}$. The Earth system: biological and ecological dimensions of global environmental change. In Encyclopedia of global environmental change (H.A. Mooney \& J.G. Canadell, eds.). Ed. John Wiley \& Sons, Ltd, Chichester, p.489-496.

RIBEIRO, M.N.G. \& ADIS, J. 1984. Local rainfall variability: A potential bias for bioecological studies in the Central Amazon. Acta Amazônica 14:159-174.

ROBERTS, J.K.M., CHANG, K., WEBSTER, C., CALLIS, J. \& WALBOT, V. 1989. Dependence of ethanolic fermentation, cytoplasmic $\mathrm{pH}$ regulation, and viability on the activity of alcohol dehydrogenase in hypoxic maize root tips. Plant Physiology 89:1275-78.

SAAB, I.N. \& SACHS, M.M. 1996. A flooding-induced xyloglucan endo-transglycosylase homolog in maize is responsive to ethylene and associated with aerenchyma. Plant Physiology 112:385-391. 
SAATCHI, S.S., HOUGHTON, R.A., DOS SANTOS ALVALA, R.C., SOARE, J.V. \& YU, Y. 2007 Distribution of aboveground live biomass in the Amazon basin. Global Change Biology 13:816-837.

SAMPAIO, G., MARENGO, J. \& NOBRE, C. 2008. A atmosfera e as mudanças climáticas. In Biologia das mudanças climáticas no Brasil (M.S. Buckeridge, org.). Ed. Rima, São Carlos, p.05-28.

SANTOS, H.P., PURGATO, E., MERCIER, H. \& BUCKERIDGE, M.S. 2004. The control of storage xyloglucan mobilization in cotyledons of Hymenaea courbaril L. Plant Physiology 135:287-299.

SCARANO, F.R. 2008. Mudanças climáticas globais: até que ponto a ecologia como ciência pode ajudar na mitigação? In Biologia das mudanças climáticas no Brasil (M.S. Buckeridge, org.). Ed. Rima, São Carlos, p.117-130.

SPRINGER, C.J. \& WARD, J.K. 2007. Flowering time and elevated atmospheric $\mathrm{CO}_{2}$. New Phytologist 176:243255.

TOURNAIRE-ROUX, C., SUTKA, M.N., JAVOT, H., GOUT, E., GERBEAU, P., LUU, D.T., BLIGNY, R. \& MAUREL, C. 2003. Cytosolic $\mathrm{pH}$ regulates root water transport during anoxic stress through gating of aquaporins. Nature 425:393-397.
VISSER, E.J.W. \& VOESENEK, L.A.C.J. 2004. Acclimation to soil flooding - sensing and signal-tranduction. Plant and Soil 254:197-214.

VOESENEK, L.A.C.J., BENSCHOP, J.J., BOU, J., COX, M.C.H., GROENEVELD, H.W., MILLENAAR, F.F., VREEBURG, R.A.M. \& PEETERS, A.J.M. 2003. Interactions between plant hormones regulate submergence-induced shoot elongation in the floodingtolerant dicot Rumex palustris. Annals of Botany 91:205-211.

WALDHOFF, D., JUNK, W.J. \& FURCH, B. 1998. Responses of three central Amazonian tree species to drought and flooding under controlled conditions. International Journal of Ecology Environment Sciences 24:237-252.

WAND, S.J.E., MIDGLEY, G.F., JONES, M.H. \& CURTIS, P.S. 1999. Responses of wild C4 and C3 grass (Poaceae) species to elevated atmospheric $\mathrm{CO}_{2}$ concentration: a met analytic test for current theories and perceptions. Global Change Biology 5:723-741.

WINGLER, A., SCHAEWEN, A.V., LEEGOOD, R.C., LEA, P.J. \& QUICK, W.P. 1998. Regulation of senescence by citokinin, sugars and light. Plant Physiology 116: 329-335. 